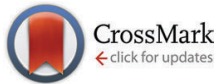

Cite this: Phys. Chem. Chem. Phys., 2015, 17, 30364

Received 4th August 2015 Accepted 19th October 2015

DOI: $10.1039 / c 5 c p 04612 b$

www.rsc.org/pccp

\title{
Stacking of the mutagenic base analogue 5-bromouracil: energy landscapes of pyrimidine dimers in gas phase and water $\$$
}

\author{
Leo F. Holroyd and Tanja van Mourik*
}

\begin{abstract}
The potential energy surfaces of stacked base pairs consisting of cytosine (C), thymine (T), uracil (U) and the mutagenic thymine analogue 5-bromouracil ( $\mathrm{BrU}$ ) have been searched to obtain all possible minima. Minima and transition states were optimised at the counterpoise-corrected M06-2X/6-31+G(d) level, both in the gas phase and in water, modelled by the polarizable continuum model. The stacked dimers studied are $\mathrm{BrU} / \mathrm{BrU}, \mathrm{C} / \mathrm{BrU}, \mathrm{C} / \mathrm{C}, \mathrm{C} / \mathrm{T}, \mathrm{C} / \mathrm{U}, \mathrm{T} / \mathrm{BrU}$ and $\mathrm{T} / \mathrm{U}$. Both face-to-back and face-to-face structures were considered. Free energies were calculated at $298.15 \mathrm{~K}$. Together with U/U, T/T and BrU/U results from previous work, these results complete the family consisting of every stacked dimer combination consisting of $\mathrm{C}, \mathrm{T}, \mathrm{U}$ and $\mathrm{BrU}$. The results were used to assess the hypothesis suggested in the literature that BrU stacks stronger than $\mathrm{T}$, which could stabilise the mispair formed by BrU and guanine. In the gas phase, structures of $\mathrm{C} / \mathrm{BrU}, \mathrm{T} / \mathrm{BrU}$ and $\mathrm{U} / \mathrm{BrU}$ with greater zero-point-corrected binding energies than $C / T, T / T$ and $U / T$, respectively, were found, with differences in favour of $B r U$ of $3.1 \mathrm{kcal} \mathrm{mol}^{-1}, 1.7 \mathrm{kcal} \mathrm{mol}^{-1}$ and $0.5 \mathrm{kcal} \mathrm{mol}^{-1}$, respectively. However, the structure of these dimers differed considerably from anything encountered in DNA. When only the dimers with the most "DNA-like" twist $\left( \pm 36^{\circ}\right)$ were considered, $\mathrm{C} / \mathrm{BrU}$ and $\mathrm{T} / \mathrm{BrU}$ were still more strongly bound than $\mathrm{C} / \mathrm{T}$ and $\mathrm{T} / \mathrm{T}$, by $0.5 \mathrm{kcal} \mathrm{mol}^{-1}$ and $1.7 \mathrm{kcal} \mathrm{mol}^{-1}$, respectively. However, when enthalpic and/or solvent contributions were taken into account, the stacking advantage of $\mathrm{BrU}$ was reversed in the gas phase and mostly nullified in water. Enhanced stacking therefore does not seem a plausible mechanism for the considerably greater ability of BrU-G mispairs over T-G mispairs to escape enzymatic repair.
\end{abstract}

\section{Introduction}

5-Bromouracil (BrU) is a base analogue of thymine $(\mathrm{T})$ which can be incorporated into DNA. It is a well-known mutagen, causing transition mutations by mispairing with guanine $(\mathrm{G})$ rather than pairing with adenine (A) during replication. ${ }^{1-7}$ This behaviour is most commonly attributed to enolisation of BrU - either in the template strand or the nucleotide pool - converting the major diketo tautomer into the "rare" enol (O4-hydroxy) tautomer, which is apparently stabilised by the bromine substituent. ${ }^{4,8-16}$ The rare tautomer mimics cytosine (C) in its hydrogen-bonding affinity, and mispairs with $\mathrm{G}$ in Watson-Crick geometry (Fig. 1, left).

EaStCHEM School of Chemistry, University of St Andrews, North Haugh, St Andrews KY16 9ST, UK. E-mail: tanja.vanmourik@st-andrews.ac.uk

$\dagger$ The research data supporting this publication can be accessed at http://dx.doi. org/10.17630/e784629e-5794-4135-8299-a49c64991a9c

\$ Electronic supplementary information (ESI) available: Methodological details; description of scans; tables with geometrical parameters and interaction energies of all optimised minima and transition states; Cartesian coordinates of optimised minima and transition states. See DOI: $10.1039 / \mathrm{c5cp} 04612 \mathrm{~b}$

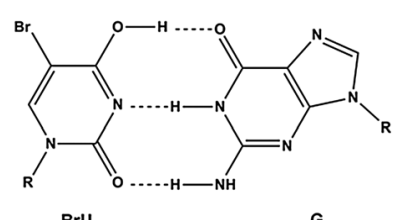

$\mathrm{BrU}$ G

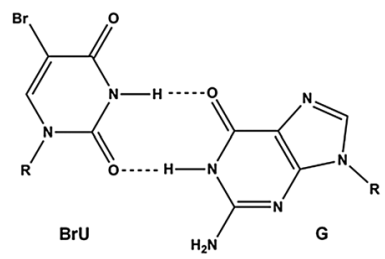

Fig. 1 Two BrU-G mispairs. Left: In Watson-Crick geometry, with the rare O4-hydroxy tautomer of BrU. Right: In wobble geometry, with the major diketo tautomer of BrU.

However, the enolised mispair has never been definitively observed during a mutagenic event.

BrU can also mispair through its major tautomer, in “wobble" (non-Watson-Crick) geometry (Fig. 1, right). ${ }^{17-19}$ As well as having only two hydrogen bonds (compared to three in the enolised mispair), the wobble pair's incorrect stereochemistry appears to make it an unlikely candidate for mutagenic replication. However, it may be stabilised against enzymatic repair (and hence be mutagenic) if it takes part in stronger base stacking interactions than the 
corresponding $\mathrm{T}-\mathrm{G}$ or $\mathrm{U}-\mathrm{G}$ wobble pairs, due to the bromine substituent. ${ }^{17}$

Stacking is certainly a determinant of the fidelity of basepair insertion during replication, especially in the presence of water, which weakens the hydrogen-bonding contribution. ${ }^{20}$ Stacking is also crucial for the thermal stability of DNA itself. ${ }^{21,22}$ Considerable effort has been devoted in recent years towards a fuller understanding of the stacking of aromatic bases, revealing a subtle blend of electrostatic, dispersive, hydrophobic, and other effects. $^{22-29}$ London dispersion is crucial, and strongly stabilising at all geometries, while electrostatics (dipole-dipole and dipole-induced dipole forces) are variously stabilising or destabilising depending on geometry. Water nullifies the geometry dependence of electrostatics, while introducing a hydrophobic bias towards the aggregation of molecules with large, electron-rich $\pi$-surfaces. Accordingly, polarisability and surface area both correlate with stacking strength. ${ }^{24}$

Bromine substituents have long been known to enhance the stacking and self-association of DNA bases, perhaps by strengthening dispersive or dipole-induced dipole forces. ${ }^{30,31}$ However, it is not clear whether BrU in particular stacks strongly enough (compared to thymine and/or uracil) to cause its greater mutagenicity. In an earlier study, we compared the stacking of BrU and $\mathrm{T}$ with natural bases in fixed experimental structures from the Protein Data Bank (PDB), and found that the gas-phase interaction energies did show some enhancement for BrU, especially when stacking with cytosine. ${ }^{32}$ We also calculated interaction energies of fully optimised $\mathrm{U} / \mathrm{BrU},^{32}$ $\mathrm{U} / \mathrm{U}^{33}$ and $\mathrm{T} / \mathrm{T}^{33}$ dimers, and found that $\mathrm{U} / \mathrm{BrU}$ was more strongly stacked than $\mathrm{U} / \mathrm{U}$ - but only in geometries that differed considerably from DNA, due to the rotation ("twist") of one base relative to the other.

In the present study, we apply the methodology of ref. 32 and 33 to investigate the energy landscapes and geometryoptimised stacking energies of the $\mathrm{BrU} / \mathrm{BrU}, \mathrm{C} / \mathrm{BrU}, \mathrm{C} / \mathrm{C}, \mathrm{C} / \mathrm{T}$, $\mathrm{C} / \mathrm{U}, \mathrm{T} / \mathrm{BrU}$ and $\mathrm{T} / \mathrm{U}$ dimers. This completes the set of pyrimidine/ pyrimidine (Pyr/Pyr) dimers including BrU. We also consider the effects of aqueous solvation and enthalpy on the relative stacking strengths of BrU, $\mathrm{U}$ and $\mathrm{T}$.

\section{Methodology}

Due to their relative lack of symmetry, DNA bases can stack in a wide range of distinct energy-minimum geometries. However, for pyrimidine dimers, the complexity is less than for purines, as the double-ring system in purines affords multiple minima with similar twist angles. ${ }^{34}$ Herein, we have applied our earlierdeveloped method of scanning the stacking energy landscapes by incremental rotation ("twisting") of one base relative to the other, followed by geometry optimisation of the resulting minima. ${ }^{32,33}$

First, the isolated monomers (BrU, U, T and C) were optimised using the M06-2X density functional ${ }^{35}$ and the 6-31+G(d) basis set, both in the gas phase and in water, modelled by the polarizable continuum model (PCM) ${ }^{36}$ using the integral equation formalism variant (IEFPCM). This functional/basis set combination

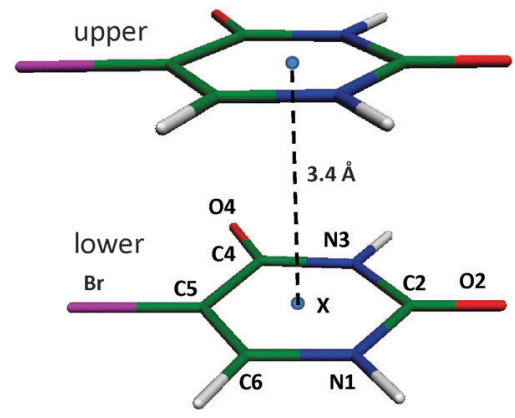

Fig. 2 Atom labelling in stacked BrU/BrU in FTB geometry. $\mathrm{X}$ are dummy atoms, placed in the geometric centre of the ring (calculated as the average of the Cartesian coordinates of the C2, C4 and C6 atoms).

was found to give stacking interaction energies in excellent agreement with high-level CCSD(T) results for stacked U/U. ${ }^{33}$ These, and all other calculations herein, were performed using Gaussian 09. ${ }^{37}$ Then, to make each of the seven dimer combinations listed above, two bases (denoted upper and lower) were placed one exactly atop the other, in their monomer-optimised geometries, at a vertical separation of $3.4 \AA$ (Fig. 2). For each dimer, two distinct stacking motifs can be created in this way: face-to-back (FTB), with the faces of both bases pointing the same way, and face-to-face (FTF), with one base flipped by $180^{\circ}$ around the C2-C5 axis so that N1(lower) is directly below N3(upper) and vice versa. We have treated both cases separately. However, only FTB stacking is important in canonical B-DNA.

Next, one base was rotated in-plane around the geometric centre of the ring (calculated as the average of the Cartesian coordinates of the $\mathrm{C} 2, \mathrm{C} 4$ and $\mathrm{C} 6$ atoms), while the other was kept fixed. This rotation was accomplished by varying the angle denoted $\tau_{\text {twist }}$, which is the dihedral defined by four atoms: O2(lower)-X(lower)-X(upper)-O2(upper), where $\mathrm{X}$ are dummy atoms at the geometric centres of each base's ring. This angle, which is analogous to the base-step parameter Helical Twist, ${ }^{38}$ was varied between $0^{\circ}$ and $355^{\circ}$ in increments of $5^{\circ}$. All other geometrical parameters were held constant. Counterpoisecorrected $^{39}$ interaction energies, $\Delta E^{\mathrm{CP}}$, were then calculated at each step with M06-2X/6-31+G(d). Due to the use of monomeroptimised geometries in the twist-angle scans, the deformation energies are zero in these scans.

The structures corresponding to minima on the resulting potential energy curves were then fully optimised at the same level of theory. The deformation energies were included in the interaction energies of the optimised dimers.

Transition states between the resulting minima were located using the synchronous transit-guided quasi-newton (STQN) method, specifically the QST3 version. ${ }^{40}$ This method requires three input geometries: two minima (for which we used the optimised structures), and one guess geometry for the transition state (for which we used the geometries that yielded energy maxima in the rigid scans). Sometimes, QST3 failed to locate a stationary point after exceeding the allowed number of optimisation steps, or encountering some other error - in these cases, the final geometry from the QST3 search was used as the starting 
geometry for a conventional transition state search, using the "Opt = TS" keyword together with the "NoEigenTest" option to suppress testing of the curvature. One or other method always successfully located a transition state.

All optimisations and transition state searches were carried out using Gaussian's “Tight” convergence criteria. All calculations employed Gaussian's “Ultrafine” integration grid (containing 99 radial shells and 590 angular points per shell). Harmonic vibrational frequencies were computed at the same level of theory, to verify the nature of the stationary points (minima or transition states), and to compute zero-point energy (ZPE) and thermal corrections to the energies, yielding the ZPE-corrected interaction energies $\left(\Delta E_{0}^{\mathrm{CP}}\right)$ and the interaction enthalpies at $298.15 \mathrm{~K}\left(\Delta H^{\mathrm{CP}}\right)$.

The above procedure was carried out separately (in parallel) in the gas phase and in water (PCM). In the PCM calculations, the counterpoise correction was applied only to the rigid scans and final optimised structures, in separate calculations without the "SCRF" keyword, as it is not possible to implement counterpoise during a PCM calculation with Gaussian.

For each optimised structure, we then computed four geometrical parameters, using an in-house Fortran 90 program previously described in ref. 33. Each of these parameters is analogous to one of the base-step parameters defined in ref. 38, but they are not formally equivalent, as our parameters are defined for stacked dimers rather than complete base steps. The parameters are the dimer twist angle $\tau_{\text {twist }}$ (analogous to Helical Twist); the vertical distance between the two stacked bases, $\delta_{\text {vert }}$ (analogous to Rise); the horizontal displacement from the position where one base is exactly on top of the other, $\delta_{\text {hor }}$ (analogous to Slide) and the angle between the two planes of the optimised stacked dimers, $\alpha_{\text {tilt }}$ (analogous to Tilt). $\tau_{\text {twist }}$ is simply the final optimised value of the O2(lower)-X(lower)$\mathrm{X}$ (upper)-O2(upper) torsion angle, which was varied during the scans. See ref. 33 or the ES1, $\neq$ for more details.

\section{Results and discussion}

The use of seven dimers (BrU/BrU, C/BrU, C/C, C/T, C/U, T/BrU and $\mathrm{T} / \mathrm{U}$ ), in both FTB and FTF orientations, in both the gas phase and water, yielded 28 stacking energy profiles and corresponding sets of minima and transition states. To keep this paper focused on the relevance of stacking to BrU mutagenicity, we have placed a more detailed description of the scans and optimised structures in the ESI, $\$$ (Sections S2 and S3) and only discuss the FTB results in the main text of the manuscript. For illustration, Fig. 3 shows the energy profiles for the seven FTB dimers in the gas phase. There are clear differences in the positions of the minima for the different dimers. All other profiles can be found in the ESI, $¥$ (Section S2). In the following section, we present the geometries and interaction energies of the most strongly bound FTB minima of each dimer, allowing a comparison of the stacking strengths of BrU, $\mathrm{U}$ and $\mathrm{T}$ when stacking with each other or with $\mathrm{C}$. Cartesian

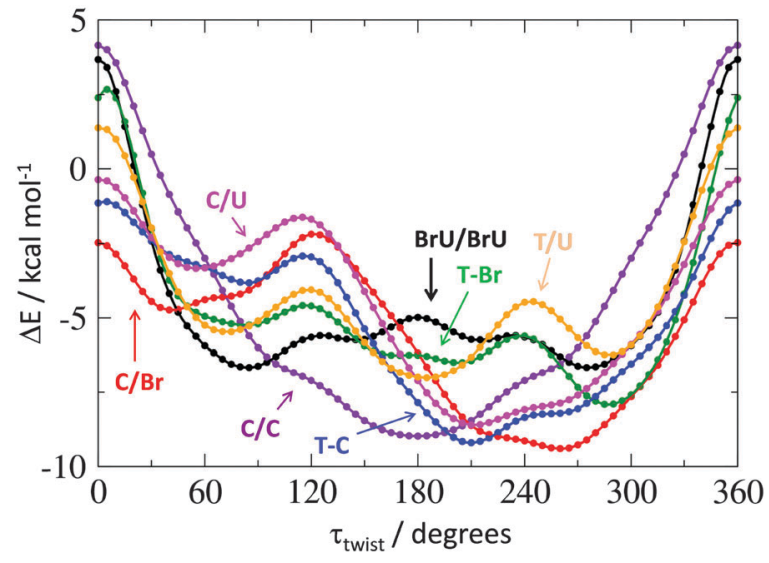

Fig. 3 Interaction energies as a function of the twist angle for the gasphase FTB BrU/BrU, C/BrU, C/C, C/T, C/U, T/BrU and T/U stacked dimers calculated at the M06-2X/6-31+G(d) level of theory.

Table 1 Interaction energies (in kcal $\mathrm{mol}^{-1}$ ) and structural parameters (distances in $\AA$, angles in degrees) of the most strongly bound face-toback minima in the gas phase for each system, calculated at the M06-2X/ $6-31+G(d)$ level of theory

\begin{tabular}{llrrrrr}
\hline System & $\tau_{\text {twist }}$ & $\alpha_{\text {tilt }}$ & $\delta_{\text {vert }}$ & $\delta_{\text {hor }}$ & $\Delta E^{\mathrm{CP}}$ & $\Delta E_{0}^{\mathrm{CP}}$ \\
\hline $\mathrm{C} / \mathrm{BrU}$ & 261 & 18 & 3.08 & 0.95 & -15.2 & -14.0 \\
$\mathrm{C} / \mathrm{T}$ & 221 & 10 & 3.13 & 0.76 & -12.1 & -10.9 \\
$\mathrm{C} / \mathrm{U}$ & 220 & 10 & 3.15 & 0.76 & -11.3 & -10.2 \\
$\mathrm{~T} / \mathrm{BrU}$ & 288 & 12 & 3.04 & 0.92 & -11.9 & -11.1 \\
$\mathrm{~T} / \mathrm{T}^{a}$ & $70 / 290$ & 14 & 3.05 & 0.90 & -10.3 & -9.4 \\
$\mathrm{~T} / \mathrm{U}$ & 182 & 6 & 3.09 & 1.23 & -9.9 & -9.3 \\
$\mathrm{U} / \mathrm{BrU}{ }^{b}$ & 287 & 12 & 3.06 & 0.89 & -10.6 & -9.8 \\
$\mathrm{U} / \mathrm{U}^{a}$ & 180 & 0 & 3.08 & 1.23 & -9.3 & -8.5 \\
$\mathrm{BrU} / \mathrm{BrU}$ & 180 & 0 & 3.15 & 1.90 & -10.8 & -10.2 \\
$\mathrm{C} / \mathrm{C}$ & 140 & 17 & 3.19 & 1.17 & -12.6 & -11.1 \\
${ }^{a}$ From ref. & $33 .{ }^{b}$ From ref. 32. & & & & \\
\hline \multicolumn{2}{l}{ From }
\end{tabular}

Table 2 Interaction energies (in $\mathrm{kcal} \mathrm{mol}^{-1}$ ) and structural parameters (distances in $\AA$, angles in degrees) of the most strongly bound face-toback minima in water PCM solvent for each system, calculated at the M06$2 \mathrm{X} / 6-31+\mathrm{G}(\mathrm{d})$ level of theory

\begin{tabular}{llrllll}
\hline System & $\tau_{\text {twist }}$ & $\alpha_{\text {tilt }}$ & $\delta_{\text {vert }}$ & $\delta_{\text {hor }}$ & $\Delta E^{\mathrm{CP}}$ & $\Delta E_{0}^{\mathrm{CP}}$ \\
\hline $\mathrm{C} / \mathrm{BrU}$ & $67 / 293$ & 10 & 3.04 & 1.16 & -7.1 & -6.4 \\
$\mathrm{C} / \mathrm{T}$ & 296 & 12 & 3.07 & 1.11 & -6.7 & -5.8 \\
$\mathrm{C} / \mathrm{U}$ & 295 & 13 & 3.08 & 1.16 & -6.0 & -5.0 \\
$\mathrm{~T} / \mathrm{BrU}$ & 291 & 6 & 3.07 & 1.10 & -6.3 & -5.9 \\
$\mathrm{~T} / \mathrm{T}^{a}$ & $61 / 299$ & 10 & 3.09 & 0.91 & -6.4 & -5.5 \\
$\mathrm{~T} / \mathrm{U}$ & 66 & 11 & 3.10 & 0.95 & -5.6 & -4.9 \\
$\mathrm{U} / \mathrm{BrU}^{b}$ & 293 & 6 & 3.09 & 1.12 & -5.5 & -5.2 \\
$\mathrm{U} / \mathrm{U}^{a}$ & $66 / 294$ & 12 & 3.12 & 0.94 & -4.7 & -4.1 \\
$\mathrm{BrU} / \mathrm{BrU}$ & $61 / 299$ & 4 & 3.09 & 1.10 & -5.6 & -5.4 \\
$\mathrm{C} / \mathrm{C}$ & $104 / 256$ & 17 & 3.15 & 1.08 & -5.6 & -4.4 \\
${ }^{a}$ From ref. & 33. & & & & &
\end{tabular}

coordinates of all optimised structures are included in the ESI, (Section S4).

Table 1 lists the geometric parameters and stacking potential energies of the most strongly bound gas-phase FTB dimers for each system, whereas Table 2 lists the geometrical parameters and stacking potential energies of the most strongly 
Table 3 Interaction energies (in $\mathrm{kcal} \mathrm{mol}^{-1}$ ) and structural parameters (distances in $\AA$, angles in degrees) of the face-to-back minima with $\tau_{\text {twist }}$ closest to $\pm 36^{\circ}$ in the gas phase, for each system, calculated at the M06$2 \mathrm{X} / 6-31+\mathrm{G}(\mathrm{d})$ level of theory

\begin{tabular}{llllllr}
\hline System & $\tau_{\text {twist }}$ & $\alpha_{\text {tilt }}$ & $\delta_{\text {vert }}$ & $\delta_{\text {hor }}$ & $\Delta E^{\mathrm{CP}}$ & \multicolumn{1}{c}{$\Delta E_{0}^{\mathrm{CP}}$} \\
\hline $\mathrm{C} / \mathrm{BrU}$ & 54 & 15 & 3.13 & 0.99 & -8.5 & -7.6 \\
$\mathrm{C} / \mathrm{T}$ & 84 & 15 & 2.90 & 2.52 & -8.1 & -7.1 \\
$\mathrm{C} / \mathrm{U}$ & 53 & 19 & 3.13 & 1.22 & -7.0 & -6.0 \\
$\mathrm{~T} / \mathrm{BrU}$ & 288 & 12 & 3.04 & 0.92 & -11.9 & -11.1 \\
$\mathrm{~T} / \mathrm{T}^{a}$ & $70 / 290$ & 14 & 3.05 & 0.90 & -10.3 & -9.4 \\
$\mathrm{~T} / \mathrm{U}$ & 71 & 16 & 3.09 & 0.87 & -8.9 & -8.1 \\
$\mathrm{U} / \mathrm{BrU}^{b}$ & 68 & 20 & 3.12 & 0.91 & -7.9 & -7.2 \\
$\mathrm{U} / \mathrm{U}^{a}$ & $72 / 288$ & 20 & 3.14 & 0.83 & -8.4 & -7.5 \\
$\mathrm{BrU} / \mathrm{BrU}$ & $73 / 287$ & 12 & 3.05 & 0.94 & -10.2 & -9.5 \\
$\mathrm{C} / \mathrm{C}$ & 140 & 17 & 3.19 & 1.17 & -12.6 & -11.1
\end{tabular}

${ }^{a}$ From ref. 33. ${ }^{b}$ From ref. 32 .

Table 4 Interaction energies (in $\mathrm{kcal} \mathrm{mol}^{-1}$ ) and structural parameters (distances in $\AA$, angles in degrees) of the face-to-back minima with $\tau_{\text {twist }}$ closest to $\pm 36^{\circ}$ in water PCM solvent, for each system, calculated at the M06-2X/6-31+G(d) level of theory

\begin{tabular}{llrllll}
\hline System & $\tau_{\text {twist }}$ & $\alpha_{\text {tilt }}$ & $\delta_{\text {vert }}$ & $\delta_{\text {hor }}$ & $\Delta E^{\mathrm{CP}}$ & $\Delta E_{0}^{\mathrm{CP}}$ \\
\hline $\mathrm{C} / \mathrm{BrU}$ & 55 & 9 & 3.16 & 0.67 & -5.2 & -4.7 \\
$\mathrm{C} / \mathrm{T}$ & 61 & 6 & 3.12 & 1.11 & -5.1 & -4.4 \\
$\mathrm{C} / \mathrm{U}$ & 60 & 6 & 3.13 & 1.21 & -4.8 & -4.1 \\
$\mathrm{~T} / \mathrm{BrU}$ & 58 & 7 & 3.10 & 0.91 & -5.7 & -5.3 \\
$\mathrm{~T} / \mathrm{T}^{a}$ & $61 / 299$ & 10 & 3.09 & 0.91 & -6.4 & -5.5 \\
$\mathrm{~T} / \mathrm{U}$ & 66 & 11 & 3.10 & 0.95 & -5.6 & -4.9 \\
$\mathrm{U} / \mathrm{BrU}^{b}$ & 293 & 6 & 3.09 & 1.12 & -5.5 & -5.2 \\
$\mathrm{U} / \mathrm{U}^{a}$ & $66 / 294$ & 12 & 3.12 & 0.94 & -4.7 & -4.1 \\
$\mathrm{BrU} / \mathrm{BrU}$ & $61 / 299$ & 4 & 3.09 & 1.10 & -5.6 & -5.4 \\
$\mathrm{C} / \mathrm{C}$ & $104 / 256$ & 17 & 3.15 & 1.08 & -5.6 & -4.4
\end{tabular}

${ }^{a}$ From ref. $33 .{ }^{b}$ From ref. 32 .

bound aqueous FTB dimers for each system. Where two values for the $\tau_{\text {twist }}$ angle are listed, these are for two symmetry-equivalent conformers. Sequential bases in conventional B-DNA stack with a Helical Twist of around $36^{\circ} \cdot{ }^{41,42}$ As can be seen in Table 1, the most strongly bound gas-phase minima for most dimers have values of $\tau_{\text {twist }}$ that differ from that of DNA by more than $100^{\circ}$. Table 3 therefore shows the gas-phase minima for each dimer that have $\tau_{\text {twist }}$ closest to $\pm 36^{\circ}$ (where $-36^{\circ} \equiv 324^{\circ}$ ), whereas Table 4

Table 5 Interaction enthalpies (in $\mathrm{kcal} \mathrm{mol}^{-1}$ ) and structural parameters (distances in $\AA$, angles in degrees) of the most strongly bound face-toback minima (by enthalpy) in the gas phase for each system, calculated at the M06-2X/6-31+G(d) level of theory

\begin{tabular}{llllll}
\hline System & $\tau_{\text {twist }}$ & $\alpha_{\text {tilt }}$ & $\delta_{\text {vert }}$ & $\delta_{\text {hor }}$ & $\Delta H^{\mathrm{CP}}$ \\
\hline $\mathrm{C} / \mathrm{BrU}$ & 261 & 18 & 3.08 & 0.95 & -9.1 \\
$\mathrm{C} / \mathrm{T}$ & 221 & 10 & 3.13 & 0.76 & -9.2 \\
$\mathrm{C} / \mathrm{U}$ & 220 & 10 & 3.15 & 0.76 & -8.5 \\
$\mathrm{~T} / \mathrm{BrU}$ & 288 & 12 & 3.04 & 0.92 & -5.5 \\
$\mathrm{~T} / \mathrm{T}^{a}$ & 180 & 0 & 3.12 & 1.22 & -7.6 \\
$\mathrm{~T} / \mathrm{U}$ & 182 & 6 & 3.09 & 1.23 & -7.4 \\
$\mathrm{U} / \mathrm{BrU}^{b}$ & 287 & 12 & 3.06 & 0.89 & -4.7 \\
$\mathrm{U} / \mathrm{U}^{a}$ & 180 & 0 & 3.08 & 1.23 & -6.9 \\
$\mathrm{BrU} / \mathrm{BrU}$ & $73 / 287$ & 12 & 3.05 & 0.94 & -1.5 \\
$\mathrm{C} / \mathrm{C}$ & 142 & 17 & 3.19 & 1.17 & -9.6
\end{tabular}

${ }^{a}$ Unpublished data from the authors of ref. $33 .{ }^{b}$ Unpublished data from the authors of ref. 32 .
Table 6 Interaction enthalpies (in $\mathrm{kcal} \mathrm{mol}^{-1}$ ) and structural parameters (distances in $\AA$, angles in degrees) of the most strongly bound face-toback minima (by enthalpy) in water PCM solvent for each system, calculated at the M06-2X/6-31+G(d) level of theory

\begin{tabular}{llrlll}
\hline System & $\tau_{\text {twist }}$ & $\alpha_{\text {tilt }}$ & $\delta_{\text {vert }}$ & $\delta_{\text {hor }}$ & $\Delta H^{\mathrm{CP}}$ \\
\hline $\mathrm{C} / \mathrm{BrU}$ & $67 / 293$ & 10 & 3.04 & 1.16 & -5.9 \\
$\mathrm{C} / \mathrm{T}$ & 296 & 12 & 3.07 & 1.11 & -5.3 \\
$\mathrm{C} / \mathrm{U}$ & 295 & 13 & 3.08 & 1.16 & -4.5 \\
$\mathrm{~T} / \mathrm{BrU}$ & 291 & 6 & 3.07 & 1.10 & -5.3 \\
$\mathrm{~T} / \mathrm{T}^{a}$ & $61 / 299$ & 10 & 3.09 & 0.91 & -5.1 \\
$\mathrm{~T} / \mathrm{U}$ & 66 & 11 & 3.10 & 0.95 & -4.3 \\
$\mathrm{U} / \mathrm{BrU}^{b}$ & 293 & 6 & 3.09 & 1.12 & -4.5 \\
$\mathrm{U} / \mathrm{U}^{a}$ & $66 / 294$ & 12 & 3.12 & 0.94 & -3.5 \\
$\mathrm{BrU} / \mathrm{BrU}$ & $61 / 299$ & 4 & 3.09 & 1.10 & -4.7 \\
$\mathrm{C} / \mathrm{C}$ & $104 / 256$ & 17 & 3.15 & 1.08 & -4.1
\end{tabular}

${ }^{a}$ Unpublished data from the authors of ref. $33 .{ }^{b}$ Unpublished data from the authors of ref. 32 .

Table 7 Interaction enthalpies (in $\mathrm{kcal} \mathrm{mol}^{-1}$ ) and structural parameters (distances in $\AA$, angles in degrees) of the face-to-back minima with $\tau$ closest to $\pm 36^{\circ}$ in the gas phase, for each system, calculated at the M06$2 \mathrm{X} / 6-31+\mathrm{G}(\mathrm{d})$ level of theory

\begin{tabular}{llllll}
\hline System & $\tau_{\text {twist }}$ & $\alpha_{\text {tilt }}$ & $\delta_{\text {vert }}$ & $\delta_{\text {hor }}$ & $\Delta H^{\mathrm{CP}}$ \\
\hline $\mathrm{C} / \mathrm{BrU}$ & 54 & 15 & 3.13 & 0.99 & -3.8 \\
$\mathrm{C} / \mathrm{T}$ & 84 & 15 & 2.90 & 2.52 & -5.3 \\
$\mathrm{C} / \mathrm{U}$ & 53 & 19 & 3.13 & 1.22 & -4.2 \\
$\mathrm{~T} / \mathrm{BrU}$ & 288 & 12 & 3.04 & 0.92 & -5.5 \\
$\mathrm{~T} / \mathrm{T}^{a}$ & $70 / 290$ & 14 & 3.05 & 0.90 & -7.5 \\
$\mathrm{~T} / \mathrm{U}$ & 71 & 16 & 3.09 & 0.87 & -6.1 \\
$\mathrm{U} / \mathrm{BrU}^{b}$ & 68 & 20 & 3.12 & 0.91 & -3.4 \\
$\mathrm{U} / \mathrm{U}^{a}$ & $72 / 288$ & 20 & 3.14 & 0.83 & -5.6 \\
$\mathrm{BrU} / \mathrm{BrU}$ & $73 / 287$ & 12 & 3.05 & 0.94 & -1.5 \\
$\mathrm{C} / \mathrm{C}$ & 140 & 17 & 3.19 & 1.17 & -9.6
\end{tabular}

${ }^{a}$ Unpublished data from the authors of ref. $33 .{ }^{b}$ Unpublished data from the authors of ref. 32 .

shows the same comparison for the aqueous phase. Table 5 lists the geometrical parameters and stacking enthalpies of the gas-phase FTB dimers that are most strongly bound in terms of enthalpy, while Table 6 provides the equivalent data for the aqueous phase. Tables 7 and 8 show the stacking enthalpies of the dimers with $\tau$ closest to $\pm 36^{\circ}$ in the gas phase and water respectively.

We wish to establish whether 5-bromouracil undergoes enhanced base stacking interactions (compared to the parent bases, uracil and thymine), when incorporated adjacent to pyrimidines in DNA, in order to evaluate the suggestion that stacking stabilises the mispairs of BrU and hence causes its mutagenicity. ${ }^{17,43}$

By potential energy, the most strongly bound FTB structure of any found in this study is the gas-phase $\mathrm{C} / \mathrm{BrU}$ dimer with $\tau_{\text {twist }}=261^{\circ}\left(\Delta E_{0}^{\mathrm{CP}}=-14.0 \mathrm{kcal} \mathrm{mol}^{-1}\right.$; Table 1). Compared to the interaction of the most strongly bound $\mathrm{C} / \mathrm{T}$ stacked dimer the difference is $3.1 \mathrm{kcal} \mathrm{mol}^{-1}$ in favour of BrU. Likewise, the interaction of the most strongly stacked FTB $\mathrm{C} / \mathrm{U}$ dimer is almost $4.0 \mathrm{kcal} \mathrm{mol}^{-1}$ weaker than in $\mathrm{C} / \mathrm{BrU}$. We can make similar observations when $\mathrm{BrU}, \mathrm{T}$ and $\mathrm{U}$ stack with either $\mathrm{T}$ or $\mathrm{U}$ (using the values listed in Table 1).

At first, therefore, the results seem to support the hypothesis that BrU undergoes stronger stacking interactions than $\mathrm{T}$ and 
Table 8 Interaction enthalpies (in $\mathrm{kcal} \mathrm{mol}^{-1}$ ) and structural parameters (distances in $\AA$, angles in degrees) of the face-to-back minima with $\tau$ closest to $\pm 36^{\circ}$ in water PCM solvent, for each system, calculated at the M06-2X/6-31+G(d) level of theory

\begin{tabular}{llrlll}
\hline System & $\tau_{\text {twist }}$ & $\alpha_{\text {tilt }}$ & $\delta_{\text {vert }}$ & $\delta_{\text {hor }}$ & $\Delta H^{\mathrm{CP}}$ \\
\hline $\mathrm{C} / \mathrm{BrU}$ & 55 & 9 & 3.16 & 0.67 & -4.1 \\
$\mathrm{C} / \mathrm{T}$ & 61 & 6 & 3.12 & 1.11 & -3.8 \\
$\mathrm{C} / \mathrm{U}$ & 60 & 6 & 3.13 & 1.21 & -3.5 \\
$\mathrm{~T} / \mathrm{BrU}$ & 58 & 7 & 3.10 & 0.91 & -4.6 \\
$\mathrm{~T} / \mathrm{T}^{a}$ & $61 / 299$ & 10 & 3.09 & 0.91 & -5.1 \\
$\mathrm{~T} / \mathrm{U}$ & 66 & 11 & 3.10 & 0.95 & -4.3 \\
$\mathrm{U} / \mathrm{BrU}^{b}$ & 293 & 6 & 3.09 & 1.12 & -4.5 \\
$\mathrm{U} / \mathrm{U}^{a}$ & $66 / 294$ & 12 & 3.12 & 0.94 & -3.5 \\
$\mathrm{BrU} / \mathrm{BrU}$ & $61 / 299$ & 4 & 3.09 & 1.10 & -4.7 \\
$\mathrm{C} / \mathrm{C}$ & $104 / 256$ & 17 & 3.15 & 1.08 & -4.1
\end{tabular}

${ }^{a}$ Unpublished data from the authors of ref. $33 .{ }^{b}$ Unpublished data from the authors of ref. 32 .

Table 9 Isotropic polarisabilities, $\alpha$, of $\mathrm{BrU}, \mathrm{T}, \mathrm{U}$ and $\mathrm{C}$, calculated in the gas phase and water (PCM) at the M06-2X/6-31+G(d) level of theory

\begin{tabular}{lrrll}
\hline & \multicolumn{1}{c}{$\mathrm{BrU}$} & $\mathrm{T}$ & $\mathrm{U}$ & $\mathrm{C}$ \\
\hline$\alpha$ (gas) $/ \mathrm{bohr}^{3}$ & 83.2 & 76.3 & 64.2 & 71.2 \\
$\alpha$ (water) $/ \mathrm{bohr}^{3}$ & 110.4 & 100.4 & 84.5 & 94.3
\end{tabular}

$\mathrm{U}$, at least when the partner base is $\mathrm{C}, \mathrm{T}$ or $\mathrm{U}$. Setting the ZPE-corrected stacking "strength" of $\operatorname{BrU}\left(\Delta E_{0}^{\mathrm{CP}}\right.$ of the strongestbound dimer) as 1.00 , the relative stacking strengths of $\mathrm{T}$ and $\mathrm{U}$ (the ratios of $\Delta E_{0}^{\mathrm{CP}}$ to that of $\mathrm{BrU}$ ) are as follows: for stacking with $\mathrm{C}$, strength of $\mathrm{T}=0.78$ and $\mathrm{U}=0.73$; for stacking with $\mathrm{T}$, strength of $\mathrm{T}=0.85$ and $\mathrm{U}=0.84$; for stacking with $\mathrm{U}$, strength of $\mathrm{T}=0.95$ and $\mathrm{U}=0.87$. These results may be related to the relative polarisabilities (Table 9). The ratio of the gas-phase polarisabilities is $\mathrm{BrU}=1.00, \mathrm{~T}=0.92$ and $\mathrm{U}=0.77$. However, a more detailed consideration of the results is necessary. Firstly, in water, the absolute stacking energies are smaller than in the gas phase, hence the differences between species are smaller. Water is present at the surface of DNA, ${ }^{44}$ and plays a crucial role in base stacking. ${ }^{27,45,46}$ Repeating the comparison of all energy minima (shown in Table 2) shows that, when stacking with $\mathrm{C}, \mathrm{T}$ or $\mathrm{U}$, the order of stacking strength is $\mathrm{BrU}>\mathrm{T}>\mathrm{U}$, as in the gas phase; however, the differences between BrU and $\mathrm{T}$ are less than $1 \mathrm{kcal} \mathrm{mol}^{-1}$. Such differences are probably smaller than the error margin of methodology employed, and are unlikely to strongly affect insertion fidelity. Secondly, thermal effects weaken the stacking of $\mathrm{BrU}$, and actually nullify the preference for BrU over $\mathrm{T}$ and $\mathrm{U}$. When the enthalpic corrections at $298.15 \mathrm{~K}$ are added, all the stacking interactions are weakened compared to $\Delta E_{0}^{\mathrm{CP}}$, but this effect is greatest for dimers containing BrU, especially in the gas phase (comparison of values in Tables 1 and 5). For dimers containing BrU the interaction of the most strongly bound gas-phase dimer is reduced by 5-6 $\mathrm{kcal} \mathrm{mol}^{-1}$, except for $\mathrm{BrU} / \mathrm{BrU}$, for which the reduction is as much as $7.7 \mathrm{kcal} \mathrm{mol}^{-1}$. In comparison, the corresponding decreases for the dimers not containing BrU are much smaller $\left(<2 \mathrm{kcal} \mathrm{mol}^{-1}\right)$. The larger decrease in interaction energy upon inclusion of thermal effects for dimers containing $\mathrm{BrU}$ is apparently correlated to the greater mass of $\mathrm{Br}$ compared to the $\mathrm{CH}_{4}$ group in $\mathrm{T}$ or the $\mathrm{H}$ atom in $\mathrm{U}$. In conclusion, when all values of $\tau_{\text {twist }}$ are allowed, and enthalpic effects are accounted for, the three bases under comparison stack in the order of strength $\mathrm{T}>\mathrm{U}>\mathrm{BrU}$ when the stacking partner is $\mathrm{T}, \mathrm{U}$ or $\mathrm{BrU}$, and in the order $\mathrm{T}>\mathrm{BrU}>\mathrm{U}$ when the stacking partner is $\mathrm{C}$. When only the values of $\tau_{\text {twist }}$ closest to $\pm 36^{\circ}$ are chosen (see Table 7), the order is $\mathrm{T}>\mathrm{U}>\mathrm{BrU}$ for all four stacking partners. In other words, in enthalpic terms, BrU takes part in weaker gas-phase stacking interactions with pyrimidines than either $\mathrm{T}$ or $\mathrm{U}$ does.

The equivalent comparison in water is shown in Table 8 . Like the aqueous potential energies, the aqueous enthalpies show very little variation among species - BrU stacks more strongly than $\mathrm{T}$ when the partner is $\mathrm{C}$, $\mathrm{U}$ or $\mathrm{BrU}$, while the reverse is true when the partner is $\mathrm{T}$, but in each case the difference between $\mathrm{T}$ and $\mathrm{BrU}$ is less than $1 \mathrm{kcal} \mathrm{mol}^{-1}$.

Thirdly, when the comparison is restricted to the dimers with $\tau_{\text {twist }}$ closest to $\pm 36^{\circ}$, even the gas-phase potential energies no longer show such a clear preference for BrU: for example, comparing Tables 1 and 3 shows that the enhanced stacking of the deepest $\mathrm{C} / \mathrm{BrU}$ minimum compared to the deepest $\mathrm{C} / \mathrm{T}$ minimum is not exhibited so strongly by the corresponding "most DNA-like" minima, which have $\tau_{\text {twist }}=54^{\circ}$ and $84^{\circ}$, and $\Delta E_{0}^{\mathrm{CP}}=7.6$ and $7.1 \mathrm{kcal} \mathrm{mol}^{-1}$, respectively.

In summary, although the gas-phase potential energies show modestly enhanced stacking of BrU, this finding does not withstand the consideration of additional factors: similarity to DNA-like geometry, water solvent, and thermal effects. When the comparison of gaseous enthalpies is restricted to dimers with DNA-like conformations, BrU is actually a weaker stacker than $\mathrm{T}$ or $\mathrm{U}$. In water, the differences between the stacking of $\mathrm{BrU}$ and $\mathrm{T}$ are negligible by both enthalpy and potential energy.

\section{Conclusions}

In combination with two previous papers, ${ }^{32,33}$ we have searched for all possible energy minima of every stacked dimer combination of BrU, U, T and C, in the gas phase and water (PCM). All the dimers except gas-phase $\mathrm{C} / \mathrm{C}$ can adopt several energyminimum geometries, which are distinguished principally by the rotation of one base about the vertical axis connecting the two bases ("twist"), and, more subtly, by variations in the angle between the base planes and the extent of their horizontal displacement. The vertical distances between the bases in the optimised geometries were consistently shorter than the known average in B-DNA (which is 3.3-3.4 $\AA^{41,42}$ by around 0.2-0.3. . This may be a consequence of the methodology used: a $\operatorname{CCSD}(\mathrm{T})$ structure for $\mathrm{U} / \mathrm{U}$ displayed an inter-base distance of $3.3 \AA^{47}$ Additional reasons for the discrepancy may be the absence of the sugar-phosphate backbone in the stacked dimers considered in this work, and the fact that the values for DNA are derived from larger nucleotides, where a particular base stacks with two consecutive bases simultaneously. 
In the gas phase, structures of $\mathrm{C} / \mathrm{BrU}, \mathrm{T} / \mathrm{BrU}$ and $\mathrm{U} / \mathrm{BrU}$ with greater zero-point-corrected binding energies than $\mathrm{C} / \mathrm{T}, \mathrm{T} / \mathrm{T}$ and $\mathrm{U} / \mathrm{T}$, respectively, were found, in which the greatest differences in favour of $\mathrm{BrU}$ were $3.1 \mathrm{kcal} \mathrm{mol}^{-1}, 1.7 \mathrm{kcal} \mathrm{mol}^{-1}$ and $0.5 \mathrm{kcal} \mathrm{mol}^{-1}$, respectively. Due to their twist angles, some of these dimers differed considerably from anything encountered in DNA; but when only the dimers with the most "DNA-like" twist $\left( \pm 36^{\circ}\right)$ were considered, $\mathrm{C} / \mathrm{BrU}$ and $\mathrm{T} / \mathrm{BrU}$ were still more strongly bound than $\mathrm{C} / \mathrm{T}$ and $\mathrm{T} / \mathrm{T}$, by $0.5 \mathrm{kcal} \mathrm{mol}^{-1}$ and $1.7 \mathrm{kcal} \mathrm{mol}^{-1}$, respectively. However, stacking in the helix is an enthalpy-driven process, and one in which water bound to DNA plays a key role $^{27,45,46}$ (though it may be partly excluded from the replication machinery) ${ }^{20,48}$ When enthalpic and/or solvent contributions were taken into account, the stacking advantage of BrU was reversed in the gas phase and mostly nullified in water.

The incorporation of BrU into DNA increases the mutation rate by a factor of between $10^{3}$ and $10^{5} \cdot .^{1,5,6,49,50}$ It has been estimated that, in the absence of proofreading enzymes, a mispairing rate of 1 in $10^{n}$ base pairs requires a free energy ratio of $1.4 \times n \mathrm{kcal} \mathrm{mol}^{-1}$ between a complementary and non-complementary base pair. ${ }^{50,51}$ In the present study, the stacking potential energy of BrU in "DNAlike" gas-phase geometries was never greater than that of thymine by more than $1.7 \mathrm{kcal} \mathrm{mol}^{-1}$ (see Table 3), and even this enhancement was largely nullified by thermal and aqueous effects. A recent paper examining the performance of the M06-2X functional reported a mean unsigned error of $2.75 \mathrm{~kJ} \mathrm{~mol}^{-1}\left(0.66 \mathrm{kcal} \mathrm{mol}^{-1}\right)$ for non-zwitterionic anionic bromide-arginine complexes and $0.85 \mathrm{~kJ} \mathrm{~mol}^{-1}\left(0.20 \mathrm{kcal} \mathrm{mol}^{-1}\right)$ for zwitterionic conformers. ${ }^{52}$ Together with the previously observed excellent performance of this functional for $\mathrm{U} / \mathrm{U}$ stacking, ${ }^{33}$ and noting that the energy differences that would be needed to implicate stacking as the cause of $\mathrm{BrU}$ mutagenicity are certainly greater than $0.66 \mathrm{kcal} \mathrm{mol}^{-1}$, M06-2X can be expected to provide sufficiently accurate results to indicate whether BrU's mutagenicity is due to enhanced stacking. The results also agree with a recent study, where we performed energy calculations on experimental geometries of stacked dimers of BrU or T stacking with all canonical DNA bases (A, C, G or T), taken from DNA structures in the Protein Data Bank. ${ }^{32}$ No strong evidence was found for the suggestion that the mutagenicity of BrU is due to enhanced stacking compared to the corresponding stacked dimers involving thymine. We therefore conclude that stacking is not a plausible mechanism for the considerably greater ability of BrU-G mispairs over T-G mispairs to escape enzymatic repair. As enhanced stacking of BrU compared to $\mathrm{T}$ or $\mathrm{U}$ is an explanatory power which the "wobble pair" model of BrU mutagenesis requires it to have, the wobble pair model is not supported by our results. Instead, we wish to draw attention to the possible role of water in forming and stabilising the "rare" enol tautomer of BrU, leading to mutagenic mispairing. ${ }^{11-13,53}$

\section{Acknowledgements}

The authors gratefully acknowledge EaStCHEM for computer time on the EaStCHEM Research Computing Facility. LFH is grateful to the Engineering and Physical Sciences Research
Council for studentship support through the Doctoral Training Account scheme (grant code EP/K503162/1).

\section{References}

1 S. Benzer and E. Freese, Proc. Natl. Acad. Sci. U. S. A., 1958, 44, 112-119.

2 E. Freese, Proc. Natl. Acad. Sci. U. S. A., 1959, 45, 622-633.

3 T. A. Trautner, M. N. Swartz and A. Kornberg, Proc. Natl. Acad. Sci. U. S. A., 1962, 48, 449-455.

4 B. E. Terzaghi, G. Streisinger and F. W. Stahl, Proc. Natl. Acad. Sci. U. S. A., 1962, 48, 1519-1524.

5 J. W. McGahen and C. E. Hoffmann, Nature, 1966, 209, 1241-1242.

6 E. R. Kaufman, Mol. Cell. Biol., 1984, 4, 2449-2454.

7 R. L. Davidson, P. Broeker and C. R. Ashman, Proc. Natl. Acad. Sci. U. S. A., 1988, 85, 4406-4410.

8 A. R. Katritzky and A. J. Waring, J. Chem. Soc., 1962, 1540-1544.

9 M. D. Topal and J. R. Fresco, Nature, 1976, 263, 285-289.

$10 \mathrm{X} . \mathrm{Hu}, \mathrm{H}$. Li, J. Ding and S. Han, Biochemistry, 2004, 43, 6361-6369.

11 V. I. Danilov, T. van Mourik, N. Kurita, H. Wakabayashi, T. Tsukamoto and D. Hovorun, J. Phys. Chem. A, 2009, 113, 2233-2235.

12 T. van Mourik, V. I. Danilov, V. V. Dailidonis, N. Kurita, H. Wakabayashi and T. Tsukamoto, Theor. Chem. Acc., 2010, 125, 233-244.

13 K. Nomura, R. Hoshino, E. Shimizu, Y. Hoshiba, V. I. Danilov and N. Kurita, J. Mod. Phys., 2013, 4, 422-431.

14 L. A. Allison, Fundamental Molecular Biology, Blackwell Publishing, Oxford, 2007.

15 D. L. Hartl, Essential Genetics: A Genomics Perspective, Jones \& Bartlett Publishers, 2009.

16 L. Fishbein, Chemical Mutagens: Environmental Effects on Biological Systems, Elsevier, 2012.

17 T. Brown, G. Kneale, W. N. Hunter and O. Kennard, Nucleic Acids Res., 1986, 14, 1801-1809.

18 E. Alexopoulos, E. A. Jares-Erijman, T. M. Jovin, R. Klement, R. Machinek, G. M. Sheldrick and I. Usón, Acta Crystallogr., Sect. D: Biol. Crystallogr., 2005, 61, 407-415.

19 R. Sanishvili, C. Besnard, F. Camus, M. Fleurant, P. Pattison, G. Bricogne and M. Schiltz, J. Appl. Crystallogr., 2007, 40, 552-558.

20 J. Petruska, L. C. Sowers and M. F. Goodman, Proc. Natl. Acad. Sci. U. S. A., 1986, 83, 1559-1562.

21 P. Yakovchuk, E. Protozanova and M. D. Frank-Kamenetskii, Nucleic Acids Res., 2006, 34, 564-574.

22 E. T. Kool, Annu. Rev. Biophys. Biomol. Struct., 2001, 30, 1-22. 23 R. A. Friedman and B. Honig, Biophys. J., 1995, 69, 1528-1535.

24 K. M. Guckian, B. A. Schweitzer, R. X.-F. Ren, C. J. Sheils, D. C. Tahmassebi and E. T. Kool, J. Am. Chem. Soc., 2000, 122, 2213-2222.

25 Ż. Czyżnikowska, R. Zaleśny, M. Ziółkowski, R. W. Gora and P. Cysewski, Chem. Phys. Lett., 2007, 450, 132-137. 
26 J. Šponer, K. E. Riley and P. Hobza, Phys. Chem. Chem. Phys., 2008, 10, 2595-2610.

27 C. A. Morgado, P. Jurečka, D. Svozil, P. Hobza and J. Šponer, J. Chem. Theory Comput., 2009, 5, 1524-1544.

28 Q. A. Smith, M. S. Gordon and L. V. Slipchenko, J. Phys. Chem. A, 2011, 115, 11269-11276.

29 J. Šponer, J. E. Šponer, A. Mládek, P. Jurečka, P. Banás and M. Otyepka, Biopolymers, 2013, 99, 978-988.

30 F. B. Howard, J. Frazier and H. T. Miles, J. Biol. Chem., 1969, 244, 1291-1302.

31 N. I. Nakano and S. J. Igarashi, Biochemistry, 1970, 9, 577-583.

32 L. F. Holroyd and T. van Mourik, Theor. Chem. Acc., 2014, 133, 1431-1443.

33 R. S. Hunter and T. van Mourik, J. Comput. Chem., 2012, 33, 2161-2172.

34 T. van Mourik and S. W. L. Hogan, Struct. Chem., in press. 35 Y. Zhao and D. G. Truhlar, Theor. Chem. Acc., 2008, 120, 215-241.

36 S. Miertus, E. Scrocco and J. Tomasi, Chem. Phys., 1981, 55, 117-129.

37 M. J. Frisch, G. W. Trucks, H. B. Schlegel, G. E. Scuseria, M. A. Robb, J. R. Cheeseman, G. Scalmani, V. Barone, B. Mennucci, G. A. Petersson, H. Nakatsuji, M. Caricato, X. Li, H. P. Hratchian, A. F. Izmaylov, J. Bloino, G. Zheng, J. L. Sonnenberg, M. Hada, M. Ehara, K. Toyota, R. Fukuda, J. Hasegawa, M. Ishida, T. Nakajima, Y. Honda, O. Kitao, H. Nakai, T. Vreven, J. A. Montgomery Jr., J. E. Peralta, F. Ogliaro, M. Bearpark, J. J. Heyd, E. Brothers, K. N. Kudin, V. N. Staroverov, R. Kobayashi, J. Normand, K. Raghavachari, A. Rendell, J. C. Burant, S. S. Iyengar, J. Tomasi, M. Cossi, N. Rega, J. M. Millam, M. Klene, J. E. Knox, J. B. Cross, V. Bakken, C. Adamo, J. Jaramillo, R. Gomperts, R. E. Stratmann, O. Yazyev, A. J. Austin, R. Cammi, C. Pomelli, J. W. Ochterski, R. L. Martin, K. Morokuma, V. G. Zakrzewski, G. A. Voth, P. Salvador, J. J. Dannenberg, S. Dapprich, A. D. Daniels, Ö. Farkas, J. B. Foresman, J. V. Ortiz, J. Cioslowski and D. J. Fox, Gaussian 09, Revision A.02, Gaussian, Inc., Wallingford Ct, 2009.
38 R. E. Dickerson, M. Bansal, C. R. Calladine, S. Diekmann, W. N. Hunter, O. Kennard, E. von Kitzing, R. Lavery, H. C. M. Nelson, W. K. Olson, W. Saenger, Z. Shakked, H. Sklenar, D. M. Soumpasis, C.-S. Tung, A. H.-J. Wang and V. B. Zhurkin, EMBO J., 1989, 8, 1-4.

39 S. F. Boys and F. Bernardi, Mol. Phys., 1970, 19, 553-566.

40 C. Peng and H. B. Schlegel, Isr. J. Chem., 1993, 33, 449-454.

41 M. A. El Hassan and C. R. Calladine, Philos. Trans. R. Soc., A, 1997, 355, 43-100.

42 W. K. Olson, M. Bansal, S. K. Burley, R. E. Dickerson, M. Gerstein, S. C. Harvey, U. Heinemann, X.-J. Lu, S. Neidle, Z. Shakked, H. Sklenar, M. Suzuki, C.-S. Tung, E. Westhof, C. Wolberger and H. M. Berman, J. Mol. Biol., 2001, 313, 229-237.

43 C. E. Bugg, J. M. Thomas, M. Sundaralingam and S. T. Rao, Biopolymers, 1971, 10, 175-219.

44 B. Schneider, D. M. Cohen, L. Schleifer, A. R. Srinivasan, W. K. Olson and H. M. Berman, Biophys. J., 1993, 65, 2291-2303.

45 M. Kabeláč and P. Hobza, Chem. - Eur. J., 2001, 7, 2067-2074.

46 V. I. Danilov, V. V. Dailidonis, T. van Mourik and H. A. Früchtl, Cent. Eur. J. Chem., 2011, 9, 720-727.

47 J. Řezáč, K. E. Riley and P. Hobza, J. Chem. Theory Comput., 2011, 7, 2427-2438.

48 A. Furmanchuk, O. Isayev, L. Gorb, O. V. Shishkin, D. Hovorun and J. Leszczynski, Phys. Chem. Chem. Phys, 2011, 13, 4311-4317.

49 B. Glickman, P. van den Elsen and M. Radman, Mol. Gen. Genet., 1978, 163, 307-312.

50 R. S. Lasken and M. F. Goodman, J. Biol. Chem., 1984, 259, 11491-11495.

51 L. A. Loeb and T. A. Kunkel, Annu. Rev. Biochem., 1982, 52, 429-457.

52 M. Walker, A. J. A. Harvey, A. Sen and C. E. H. Dessent, J. Phys. Chem. A, 2013, 117, 12590-12600.

53 T. van Mourik and M.-P. Gaigeot, Modelling the Dynamics of the Keto-Enol Tautomerisation of Uracil and 5-Bromouracil Using First Principles Molecular Dynamics, 2011. 